\title{
What Is a Legitimate, Low-Quality, or Predatory Surgery Journal?
}

\author{
Jaime A. Teixeira da Silva ${ }^{1}$ \\ Received: 13 December 2020 / Accepted: 7 January 2021 / Published online: 17 January 2021 \\ (C) Association of Surgeons of India 2021
}

\section{Dear Editor in Chief, Indian Journal of Surgery,}

A recent paper in the Indian Journal of Surgery sends out a somewhat alarming message to the world of surgery, namely to be careful and observant of "predatory" surgery journals that may be a "menace" [1]. The overall cautious message by Bhattacharya is appreciated because, in the age of COVID-19, publication in "predatory" venues, publication of pseudo-science by "predatory" authors, or even poorly vetted or excessively rapidly processed papers in peer-reviewed journals may negatively impact individual health, public perception, or health policies [2]. Jeffrey Beall originally coined the term "predatory publishing" and offered an alert system to this phenomenon through his blog [3]. Yet, some potential misconceptions are worth clarifying so as not to simultaneously invoke misinformation or panic through overly alarmist messages like those of Beall or Bhattacharya.

Bhattacharya did offer a broad and unspecific definition of what a "predatory" journal is, based on the opinion of select academics [4], but he was apparently unable to appreciate the unsubtle and unsettling conclusion that they reached, namely that what constitutes a "predatory" entity remains unclear. Consequently, there is no reliable list of "predatory" entities (i.e., blacklists) or "safe" entities (i.e., whitelists) because such lists suffer from type I and II errors that exist due to biases and differing levels of sensitivities [5]. Consequently, depending on the sensitivity of criteria and pre-study bias, and on the ability to transparently and independently verify qualities of a journal or publisher to assess if they meet those criteria, it is reasonable to argue that a blacklist may erroneously include a valid "scholarly" entry or fail to include (due to its incomplete nature) a truly "predatory" entity, or vice versa. Surgeons should be aware of these risks of blacklists and whitelists [6], and the biases of their creators, before they take the advice

Jaime A. Teixeira da Silva

1 Miki-cho, Kagawa-ken, Japan by Bhattacharya at face value and, perhaps too eagerly, reach a conclusion about a whitelisted or blacklisted surgical journal.

India is no stranger to the complexities of offering misguided advice to academics, sometimes erroneously, such as the UGC lists that were flawed because they relied directly on Beall's flawed criteria and blacklists [7]. If academics or their institutes, journals, publishers, education ministries, or funders insist on relying on whitelists or blacklists to make a decision regarding what is a bona fide "scholarly" journal, they need to consider those lists' inherent flaws. They should triangulate those risks with as many positive and negative indicators available and with the veracity of a paper's evidence, and not rely blindly on the "prestige" of the journal or publisher.

There is no doubt that risky (i.e., unsafe to use or cite) and unscholarly literature exists in truly "predatory" surgical journals, but there is increasing evidence that risky literature exists in journals that are traditionally perceived to be "safe", such as indexed journals or those carrying a metric [8]. Consequently, surgeons need to appreciate, through critical evaluation, and not mere blind trust based on white- or blacklisted perceptions, the intrinsic value, and flaws, of each paper.

Author Contributions The author contributed solely to the intellectual discussion underlying this paper, literature exploration, writing, reviews and editing, and accepts responsibility for the content and interpretation.

\section{Compliance with Ethical Standards}

Conflict of Interest The author declares that there are no conflicts of interest.

\section{References}

1. Bhattacharya K (2020) Predatory surgical journals - a menace to the academic world. Indian J Surg (in press). https://doi.org/10.1007/ s12262-020-02656-3 
2. Teixeira da Silva JA (2020) An alert to COVID-19 literature in predatory publishing venues. J Acad Libr 46(5):102187. https://doi. org/10.1016/j.acalib.2020.102187

3. Beall J (2012) Predatory publishers are corrupting open access. Nature. 489(7415):179. https://doi.org/10.1038/489179a

4. Grudniewicz A, Moher D, Cobey KD, Bryson GL, Cukier S, Allen K, Ardern C, Balcom L, Barros T, Berger M, Ciro JB, Cugusi L, Donaldson MR, Egger M, Graham ID, Hodgkinson M, Khan KM, Mabizela M, Manca A, Milzow K, Mouton J, Muchenje M, Olijhoek T, Ommaya A, Patwardhan B, Poff D, Proulx L, Rodger M, Severin A, Strinzel M, Sylos-Labini M, Tamblyn R, van Niekerk M, Wicherts JM, Lalu MM (2019) Predatory journals: no definition, no defence. Nature. 576(7786):210-212. https://doi.org/10.1038/ d41586-019-03759-y

5. Tsigaris P, Teixeira da Silva JA (2020) Why blacklists are not reliable: a theoretical framework. J Acad Libr (in press). https://doi.org/ 10.1016/j.acalib.2020.102266
6. Teixeira da Silva JA, Tsigaris P (2020) Issues with criteria to evaluate blacklists: an epidemiological approach. J Acad Libr 46(1): 102070. https://doi.org/10.1016/j.acalib.2019.102070

7. Patwardhan B, Nagarkar S, Gadre SR, Lakhotia SC, Katoch VM, Moher D (2018) A critical analysis of the 'UGC-approved list of journals'. Curr Sci 114(6):1299-1303. https://doi.org/10.18520/cs/ v114/i06/1299-1303

8. Cortegiani A, Ippolito M, Ingoglia G, Manca A, Cugusi L, Severin A et al (2020) Citations and metrics of journals discontinued from Scopus for publication concerns: the GhoS(t)copus Project. F1000Research 9:415. https://doi.org/10.12688/f1000research. 23847.2

Publisher's Note Springer Nature remains neutral with regard to jurisdictional claims in published maps and institutional affiliations. 